Article

\title{
Effect of Acrylamide Supplementation on the Population of Vasoactive Intestinal Peptide (VIP)-Like Immunoreactive Neurons in the Porcine Small Intestine
}

\author{
Katarzyna Palus *(D), Michał Bulc $\mathbb{D}$ and Jarosław Całka \\ Department of Clinical Physiology, Faculty of Veterinary Medicine, University of Warmia and Mazury \\ in Olsztyn, 10-719 Olsztyn, Poland; michal.bulc@uwm.edu.pl (M.B.); calkaj@uwm.edu.pl (J.C.) \\ * Correspondence: katarzyna.palus@uwm.edu.pl
}

Received: 3 November 2020; Accepted: 16 December 2020; Published: 18 December 2020

\begin{abstract}
Acrylamide is one of the harmful substances present in food. The present study aimed to establish the effect of acrylamide supplementation in tolerable daily intake (TDI) dose $(0.5 \mu \mathrm{g} / \mathrm{kg}$ b.w./day) and a dose ten times higher than TDI ( $5 \mu \mathrm{g} / \mathrm{kg} \mathrm{b.w./day)} \mathrm{on} \mathrm{the} \mathrm{population} \mathrm{of}$ vasoactive intestinal peptide-like immunoreactive (VIP-LI) neurons in the porcine small intestine and the degree of the co-localization of VIP with other neuroactive substances (neuronal nitric oxide synthase (nNOS), substance P (SP), and cocaine- and amphetamine-regulated transcript peptide (CART)). In our work, 15 Danish landrace gilts (5 in each experimental group) received capsules (empty or with low or high doses of acrylamide) for a period of 28 days with their morning feeding. Using double immunofluorescence staining, we established that acrylamide supplementation increased the number of neurons showing immunoreactivity towards VIP in all types of enteric nervous system (ENS) plexuses and fragments of the small intestine studied. Moreover, both doses of acrylamide led to changes in the degree of co-localization of VIP with NNOS, SP, and CART in intramural neurons. The observed changes may be the adaptation of neurons to local inflammation, oxidative stress, or the direct toxic effects of acrylamide on intestinal neurons, also referred to as neuronal plasticity.
\end{abstract}

Keywords: acrylamide; vasoactive intestinal peptide; small intestine; enteric nervous system; pig

\section{Introduction}

In recent years, consumer awareness has increased, and stricter legal regulations have forced food producers to control the levels and limit the presence of harmful substances in food that may have a negative impact on human health and life. One of these substances is acrylamide (ACM). The presence of ACM in food was initially detected in 2002 and since then scientists have been trying to develop methods to reduce the compound in food [1]. Large amounts of ACM have been confirmed in high-carbohydrate, heat-treated food products. It is formed in the Maillard reaction between free asparagine and reducing sugars (glucose, fructose) during thermal processing (above $120{ }^{\circ} \mathrm{C}$ ), such as frying, baking, toasting, grilling, and extrusion [2]. ACM is also formed in the process of roasting coffee beans, cocoa, and cereals [1,2]. It was estimated that people consume from 0.3 to $0.8 \mu \mathrm{g} / \mathrm{kg}$ of body weight of acrylamide contained in food products per day [3]. In the light of previous research, ACM consumed with food causes numerous homeostatic disorders in the body, showing teratogenic, genotoxic, neurotoxic effects, or disorders of reproductive functions $[1,4,5]$. To date, the results of epidemiological studies have not provided conclusive evidence of the relationship between the dietary intake of ACM and the increased risk of cancer in humans. However, based on available animal 
studies, the International Agency for Research on Cancer (IARC) classified it as "possibly carcinogenic to humans" (Group 2A) [6]. In turn, there are reports describing the neurotoxic effect of ACM on the human body [7]. Although the gastrointestinal (GI) tract is one of the main ways of ACM absorption [8], many issues related to its effect on the gut remain unclear.

The digestive tract along its entire length possesses intramural neurons grouped into plexuses that represent the enteric nervous system (ENS). It is the third part of the autonomic nervous system and is able to coordinate the work of the GI tract without the involvement of the central nervous system (CNS) $[9,10]$. The anatomical structure of the plexuses and their arrangement in the GI wall show differences, both interspecies and between digestive tract segments. It has been shown that in large mammals (including pigs), in the upper part of the GI tract (esophagus and stomach), the ENS is organized into two plexuses: the myenteric plexus (MP) and the submucous plexus ( $\mathrm{SmP}$ ). In the small and large intestines, two submucous plexuses are distinguished: the outer submucous plexus (OSP) and the inner submucous plexus (ISP) [10,11].

ENS neurons synthesize and release many neurochemicals that act as neurotransmitters or neuromodulators [9]. Each of neurons, depending on its function, can synthesize more than one neuroactive substance. This phenomenon, called the neurochemical coding of neurons, can distinguish functional classes of neurons, including inhibitory and excitatory motor neurons, vasomotor neurons, interneurons, and sensory neurons [12]. Due to the functional richness and the large number of cells that form the ENS, it is known as the "gut brain" and is able to coordinate many physiological functions in the digestive tract, such as ensuring the optimal secretion of digestive juices through the stomach, local blood flow, intestinal epithelial substance transport, gastrointestinal immune response and inflammatory process, or regulating intestinal peristalsis [10]. Moreover, numerous disorders of the GI tract trigger a response from ENS neurons, which aims at restoring the balance of the body and is expressed mainly as a change in the level of neurotransmitters $[11,13,14]$. Among the many neuroactive substances described in the ENS structures, one of the most important neuropeptides engaged in the control of both physiological and pathological states in the digestive tract is the vasoactive intestinal peptide (VIP).

VIP, a 28-amino acid peptide, was first identified in the porcine intestine in 1970 [15]. Since then, its presence has been described in reproductive, digestive, respiratory, immune, and circulatory systems as well as in the neurons of the central and peripheral nervous systems [16-18]. It is worth emphasizing that in the GI tract, VIP acts as both a neurotransmitter and a gastrointestinal hormone, belonging to the group of the so-called brain-gut hormones [16]. VIP is an inhibitory neurotransmitter well-known for its vasodilator effect and its inhibition of smooth muscle contractility [19]. In addition, VIP has a beneficial effect on the integrity of the gastrointestinal mucosa, protects the gastric and duodenal mucosa, and promotes ulcer healing [20]. Furthermore, it is noteworthy that VIP is an important factor involved in the control of various pathological processes. Previous reports have confirmed its participation in defense processes in the central and peripheral nervous systems, with an emphasis on its neuroprotective properties [13,21]. Moreover, VIP exhibits an anti-inflammatory effect, and an increase in VIP expression was noted in the course of numerous inflammatory processes, as well as in the neoplastic changes in the intestines and during the exposure of the body to toxins $[11,13,14,22,23]$. Bearing in mind the abovementioned properties of VIP and its widespread occurrence in the ENS structures in the small intestine (which is the main site of absorption of the acrylamide contained in food products), we may suspect that it may be involved in defending ENS neurons from the damaging effects of acrylamide. Thus, the present study aims to establish the effect of ACM supplementation in a tolerable daily intake (TDI) dose and a dose ten times higher than TDI on the population of VIP-like immunoreactive (VIP-LI) neurons in the porcine small intestine. Additionally, the degree of the co-localization of VIP with other neuroactive substances known for their neuroprotective properties (neuronal nitric oxide synthase (nNOS), substance P (SP) and cocaine- and amphetamine-regulated transcript peptide (CART)) is studied. This study is conducted using a pig model due its similar 
anatomical structure and life processes, and the fact that the pig is an omnivorous animal used extensively in the study of gastrointestinal diseases [24].

\section{Results}

\subsection{The Number of VIP-Positive ENS Neurons}

The presence of neurons showing immunoreactivity to VIP was confirmed in all intramural plexuses studied (the MP, OSP, and ISP) in each part of the porcine small intestine (duodenum, jejunum, and ileum) (Figure 1). In the MP, the population of VIP-positive neurons accounted for $12.14 \pm 0.31 \%$ of all PGP 9.5 positive neurons in the duodenum (Figure 1A). A similar number of VIP-LI cell bodies were observed in the jejunum (11.70 $\pm 0.33 \%)$ (Figure $1 \mathrm{~B})$ and ileum $(13.40 \pm 1.21 \%)$ (Figure 1C,D). In the OSP, the most numerous group of VIP-LI neurons was observed in the jejunum $(14.54 \pm 0.33 \%)$ (Figure 1B) and slightly fewer in the ileum (11.90 $\pm 0.29 \%$ ) (Figure 1C,G) and duodenum $(11.00 \pm 0.08 \%)$ (Figure 1A), whereas in the ISP, higher numbers of VIP-LI cell bodies were noted in the ileum (14.38 $\pm 0.98 \%$ ) (Figure $1 \mathrm{C}$ ) and jejunum (14.02 $\pm 0.64 \%$ ) (Figure 1B). The least numerous population of VIP-positive neurons was found in the duodenum (10.96 $\pm 0.65 \%)$ (Figure 1A,J).
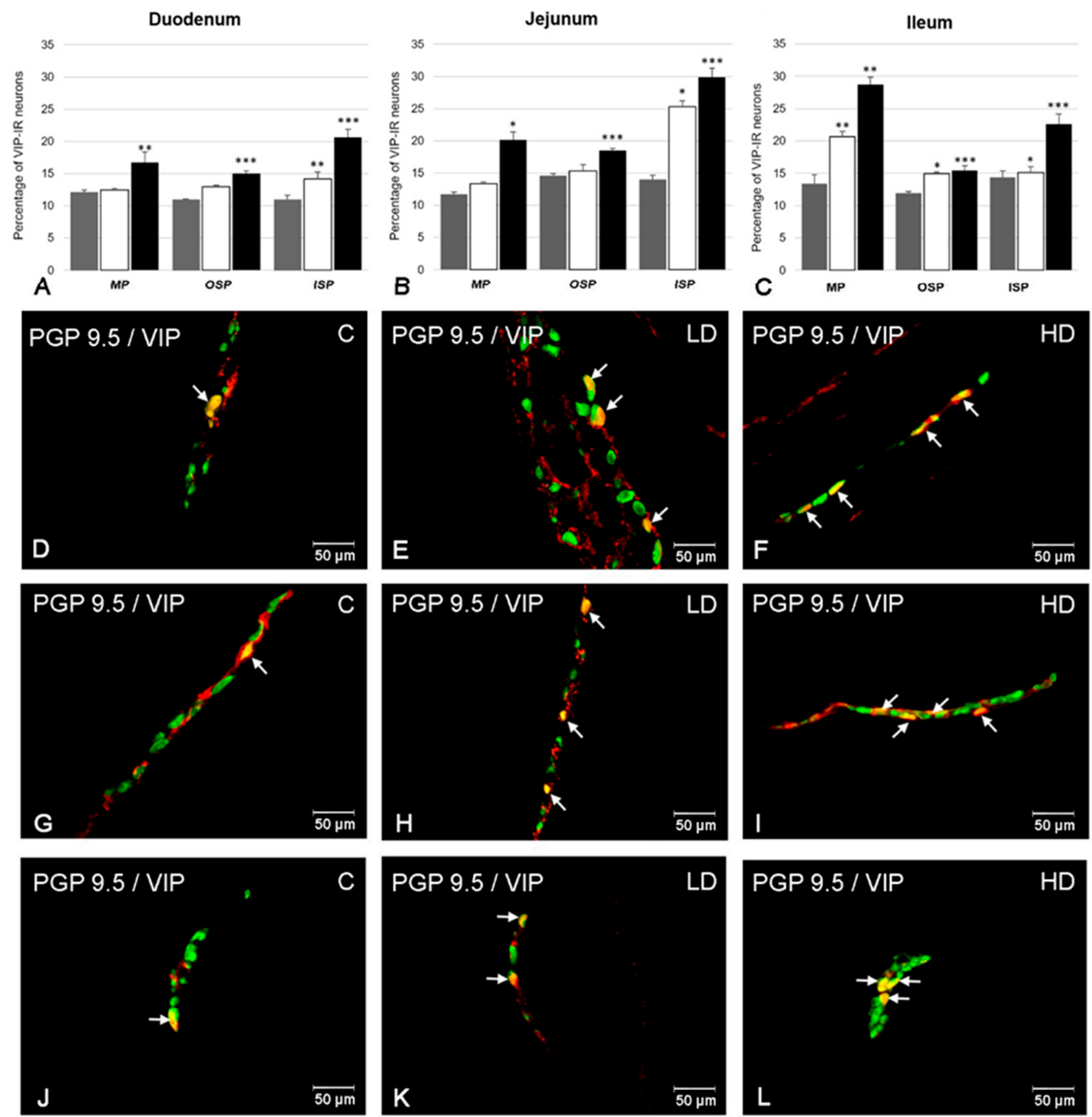

Figure 1. The number of vasoactive intestinal peptide-like immunoreactive (VIP-LI) neurons in the myenteric plexus (MP), outer submucous plexus (OSP), and inner submucous plexus (ISP) in each part of the porcine small intestine (duodenum, jejunum, and ileum) in all experimental groups (A-C) and 
the most representative images showing neurons immunoreactive to protein gene-product 9.5 (PGP 9.5)—used as a pan-neuronal marker and vasoactive intestinal peptide (VIP) in animals from control (D,G,J), low-dose (LD) $(\mathbf{E}, \mathbf{H}, \mathbf{K})$ and high-dose (HD) $(\mathbf{F}, \mathbf{I}, \mathbf{L})$ group. (A) Mean $( \pm$ SEM) percentage of VIP-LI neurons in the duodenum in animals from control (grey bar), LD (white bar) and HD (black bar) group; (B) Mean $( \pm$ SEM) percentage of VIP-LI neurons in the jejunum in animals from control (grey bar), LD (white bar), and HD (black bar) group; (C) Mean $( \pm$ SEM) percentage of VIP-LI neurons in the ileum in animals from control (grey bar), LD (white bar), and HD (black bar) group; (D) VIP-LI neurons in the MP of the ileum in animals from control group; (E) VIP-LI neurons in the MP of the ileum in animals from LD group; (F) VIP-LI neurons in the MP of the ileum in animals from HD group; (G) VIP-LI neurons in the OSP of the ileum in animals from control group; (H) VIP-LI neurons in the OSP of the ileum in animals from LD group; (I) VIP-LI neurons in the OSP of the ileum in animals from HD group; (J) VIP-LI neurons in the ISP of the duodenum in animals from control group; (K) VIP-LI neurons in the ISP of the duodenum in animals from LD group; (L) VIP-LI neurons in the ISP of the duodenum in animals from HD group. All images were created by digital superimposition of two color channels (green for PGP 9.5 and red for VIP). Intramural neurons positive to VIP are indicated with arrows. Significant differences were assessed with one-way analysis of variance (ANOVA) with Dunnett's test $\left.{ }^{*} p<0.05,{ }^{* *} p<0.01,{ }^{* * *} p<0.001\right)$.

Acrylamide supplementation affected the immunohistochemical characteristics of ENS neurons in the porcine small intestine. An increase in the number of neurons showing immunoreactivity towards VIP was noted in all studied fragments (Figure 1). The most remarkable changes were noted in the ISP, in which a statistically important increase was observed in both experimental groups (LD and HD) in all parts of the intestine (duodenum: from $10.96 \pm 0.65 \%$ in the $C$ group to $14.21 \pm 1.03 \%$ in the LD group and to $20.65 \pm 1.23 \%$ in the HD group (Figure $1 \mathrm{~A}, \mathrm{~J}-\mathrm{L}$ ); jejunum: from $14.02 \pm 0.64 \%$ to $25.27 \pm 0.94 \%$ and to $29.92 \pm 1.32 \%$ (Figure $1 \mathrm{~B}$ ); ileum: from $14.38 \pm 0.98 \%$ to $15.09 \pm 0.91 \%$ and $22.62 \pm 1.52 \%$ (Figure $1 \mathrm{C}$ ), respectively). In the OSP, a statistically important increase was noted in animals receiving low and high doses of acrylamide only in the ileum (from $11.90 \pm 0.29 \%$ to $14.93 \pm 0.26 \%$ and to $15.45 \pm 0.69 \%$ ) (Figure 1C,G-I), whereas in the duodenum and jejunum, only in the HD group was the increase statistically significant (from $11.00 \pm 0.08 \%$ to $14.96 \pm 0.45 \%$ (Figure $1 \mathrm{~A}$ ) and from $14.54 \pm 0.33 \%$ to $18.47 \pm 0.37 \%$ (Figure 1B), respectively). Similarly, in the MP, increased numbers of VIP-LI cell bodies were noted in both LD and HD groups only in the ileum (from $13.40 \pm 1.38 \%$ in group C to $20.68 \pm 0.81 \%$ in the LD group and to $28.7 \pm 1.21 \%$ in the HD group) (Figure $1 \mathrm{C}-\mathrm{F}$ ). In the duodenum and jejunum in the HD group, the increase was also significant (from $12.14 \pm 0.31 \%$ to $16.71 \pm 1.63 \%$ (Figure $1 \mathrm{~A}$ ) and from $11.70 \pm 0.33 \%$ to $20.14 \pm 1.27 \%$ (Figure $1 \mathrm{~B}$ ).

\subsection{The Co-Localization of VIP with $n$ NOS}

nNOS immunoreactivity was noted in VIP-positive ENS neurons in each kind of enteric plexus and all parts of the studied intestine (Figure 2). A higher number of VIP+/nNOS+ neurons in the MP were found in the ileum $(34.20 \pm 1.00 \%$ ) (Figure 2C,D). A smaller population of neurons simultaneously containing VIP and nNOS were observed in the jejunum (22.91 $\pm 0.25 \%$ ) (Figure $2 \mathrm{~B}$ ) and the duodenum $(13.11 \pm 1.31 \%)$ (Figure $2 \mathrm{~A})$. In the OSP, the most numerous group of VIP-LI neurons showing the presence of nNOS was detected in the jejunum $(41.20 \pm 2.19 \%$ ) (Figure 2B,G), while slightly less were observed in the duodenum $(34.38 \pm 2.31 \%)$ (Figure $2 \mathrm{~A})$ and the least were in the ileum $(29.30 \pm 1.77 \%)$ (Figure 2C). In turn, in the ISP, in the duodenum $41.98 \pm 2.12 \%$ of VIP-LI neurons were nNOS-positive (Figure 2A); in the jejunum the levels were $35.92 \pm 1.35 \%$ (Figure 2B,J), and in the ileum the levels were $30.38 \pm 2.21 \%$ (Figure 2C). 

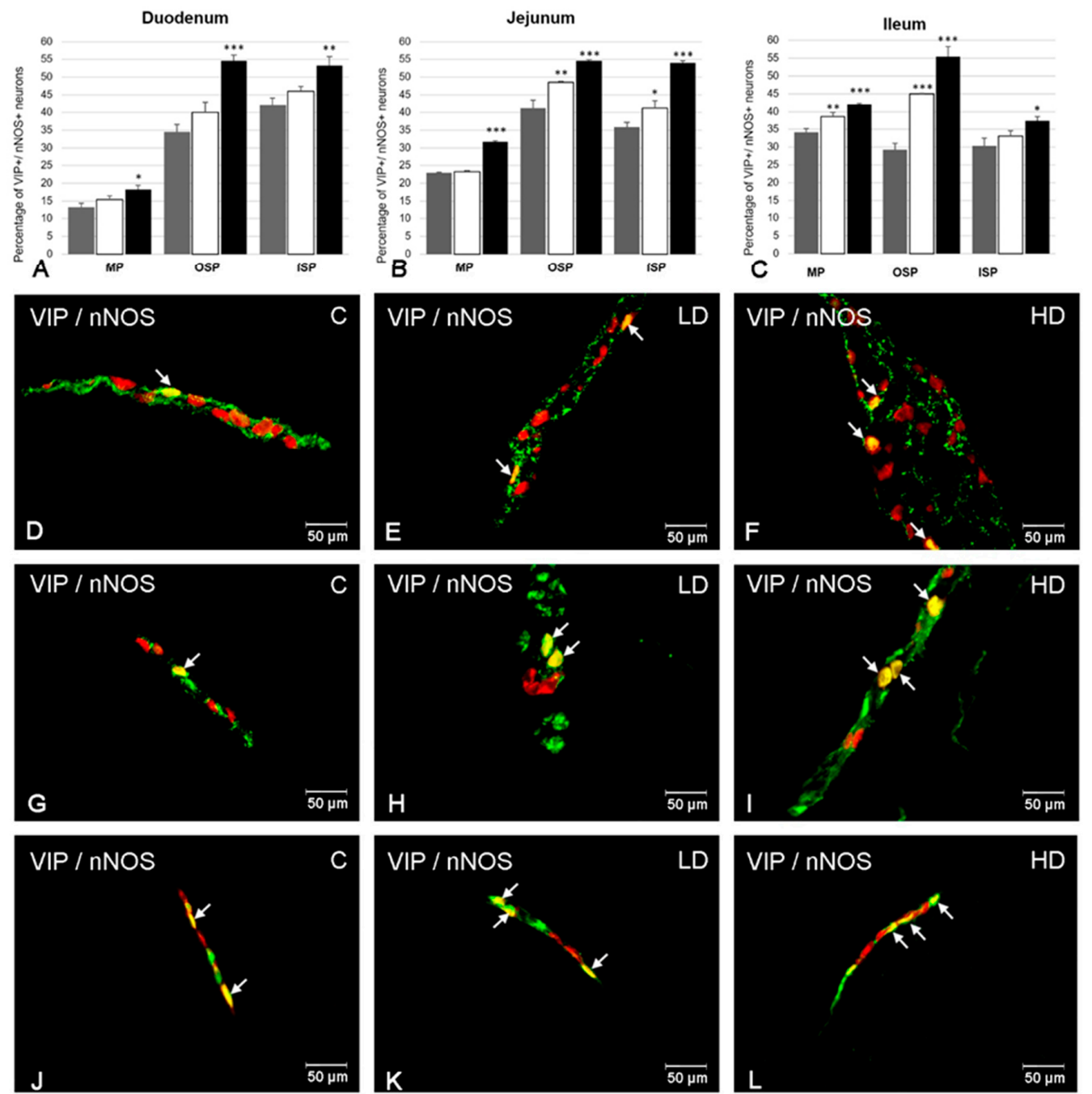

Figure 2. The ratio of co-localization of VIP with nNOS in intramural neurons in each part of the porcine small intestine (duodenum, jejunum and ileum) in control animals (grey bars), after low (white bars) and high doses (black bars) of acrylamide supplementation $(\mathbf{A}-\mathbf{C})$ and the most representative images showing VIP-LI neurons simultaneously immunoreactive to nNOS in animals from control (D,G,J), LD $(\mathbf{E}, \mathbf{H}, \mathbf{K})$ and HD $(\mathbf{F}, \mathbf{I}, \mathbf{L})$ group. (A) Mean $( \pm$ SEM) percentage of $\mathrm{VIP}+/$ nNOS+ neurons in the myenteric plexus (MP), outer submucous plexus (OSP), and inner submucous plexus (ISP) within the porcine duodenum; (B) Mean $( \pm \mathrm{SEM})$ percentage of $\mathrm{VIP}+/ \mathrm{nNOS}+$ neurons in the myenteric plexus (MP), outer submucous plexus (OSP), and inner submucous plexus (ISP) within the porcine jejunum; (C) Mean $( \pm \mathrm{SEM})$ percentage of $\mathrm{VIP}+/ \mathrm{nNOS}+$ neurons in the myenteric plexus (MP), outer submucous plexus (OSP), and inner submucous plexus (ISP) within the porcine ileum; (D) VIP+/nNOS+ neurons in the myenteric plexus of the porcine ileum in animals from control group; (E) $\mathrm{VIP}+/ \mathrm{nNOS}+$ neurons in the myenteric plexus (MP) of the porcine ileum in animals from LD group; (F) VIP+/nNOS+ neurons in the myenteric plexus (MP) of the porcine ileum in animals from HD group; (G) VIP+/nNOS+ neurons in the outer submucous plexus (OSP) of the porcine jejunum in animals from control group; (H) $\mathrm{VIP}+/ \mathrm{nNOS}+$ neurons in the outer submucous plexus (OSP) of the porcine jejunum in animals from LD group; (I) VIP+/nNOS+ neurons in the outer submucous plexus (OSP) of the porcine jejunum in animals from HD group; (J) VIP+/nNOS+ neurons in the inner submucous plexus (ISP) of the porcine jejunum in animals from control group; (K) VIP+/nNOS+ neurons in the inner submucous plexus (ISP) of the porcine jejunum in animals from LD group; (L) VIP+/nNOS+ neurons in the inner submucous plexus (ISP) of the porcine jejunum in animals from control group. All images were created by digital superimposition of two color channels (green for VIP and red for $\mathrm{nNOS}$ ). Intramural neurons immunopositive to VIP and nNOS are indicated with arrows. Significant differences were assessed with one-way analysis of variance (ANOVA) with Dunnett's test $\left({ }^{*} p<0.05,{ }^{* *} p<0.01,{ }^{* * *} p<0.001\right)$. 
Acrylamide caused significant changes in the number of VIP-positive neurons that are simultaneously immunoreactive to nNOS (Figure 2). In the MP, the most remarkable changes in the percentage of $\mathrm{VIP}+/ \mathrm{nNOS}+$ neurons were observed in the ileum, in which both doses of acrylamide evoked a significant increase (to $38.68 \pm 1.13 \%$ in the LD group and to $42.07 \pm 0.25 \%$ in the HD group) (Figure 2C-F). However, in the duodenum and jejunum, important changes were observed only in the HD group (an increase to $18.28 \pm 1.12 \%$ (Figure $2 \mathrm{~A}$ ) and to $31.70 \pm 0.33 \%$ (Figure $2 \mathrm{~B}$ ), respectively). In the OSP, both doses of acrylamide changed the degree of co-localization of VIP and nNOS in the ileum (to $44.93 \pm 0.26 \%$ in the LD group and to $55.45 \pm 2.8 \%$ in the HD group) (Figure 2C) as well as in the jejunum (to $48.47 \pm 0.37 \%$ in the LD group and to $54.54 \pm 0.33 \%$ in the HD group) (Figure 2B,G-I), while in the duodenum only a high dose of acrylamide evoked a significant increase in the number of VIP $+/ \mathrm{nNOS}+$ cell bodies (to $54.62 \pm 1.53 \%$ ) (Figure 2A). In turn, in the ISP, only in the jejunum in both experimental groups was an increased population of VIP-LI neurons simultaneously containing nNOS noted (to $41.27 \pm 2.03 \%$ in the LD group and to $54.02 \pm 0.64 \%$ in the HD group) (Figure 2B,J-L). However, only supplementation of a high dose of acrylamide changed the ratio of VIP $+/$ nNOS+ neurons in the duodenum and ileum (an increase to $53.27 \pm 2.45 \%$ and $37.42 \pm 1.21 \%$, respectively) (Figure $2 \mathrm{~A}, \mathrm{C}$ ).

\subsection{The Co-Localization of VIP with SP}

In the control group, a higher degree of co-localization of VIP with SP was noted in the MP in the duodenum $(58.74 \pm 1.69 \%)$ (Figure $3 \mathrm{~A})$ and slightly less in the ileum $(53.33 \pm 1.17)$ (Figure 3C) and the jejunum $(47.42 \pm 0.88 \%$ ) (Figure $3 \mathrm{~B}, \mathrm{D})$. Similarly, in the OSP, a higher population of VIP+/SP+ neurons were observed in the duodenum $(22.27 \pm 1.66 \%$ ) (Figure $3 \mathrm{~A}, \mathrm{G})$, than in the ileum $(21.1 \pm 0.6 \%$ ) (Figure 3C) or the jejunum (20.24 $\pm 0.57 \%$ ) (Figure 3B). In the ISP, the co-localization of VIP with SP was also the highest in the duodenum $(30.46 \pm 1.37 \%)$ (Figure $3 \mathrm{~A}, \mathrm{~J})$, followed by the jejunum $(27.73 \pm 0.66 \%)$ (Figure $3 \mathrm{~B}$ ) and the ileum $(25.58 \pm 1.48 \%$ ) (Figure 3C).

Supplementation of both low and high doses of acrylamide evoked changes in the proportion of co-localization of VIP with SP in all kinds of intestinal plexuses examined (Figure 3). Both the low and high doses of acrylamide increased the population of VIP+/SP+ neurons in the ISP in all sections of the intestine studied. A higher increase was noted in the duodenum (to $41.94 \pm 0.77 \%$ in the LD group and to $47.53 \pm 1.38 \%$ in the HD group) (Figure 3A,J-L), slightly smaller in the jejunum (to $33.33 \pm 1.28 \%$ in the LD group and to $45.40 \pm 0.74 \%$ in the HD group) (Figure $3 \mathrm{~B}$ ) and the smallest in the ileum (to $32.62 \pm 1.86 \%$ in the LD group and to $44.22 \pm 1.31 \%$ in the HD group) (Figure 3C). In the MP, the changes were significant in both experimental groups in the jejunum (an increase to $55.57 \pm 1.55 \%$ in LD group and to $63.25 \pm 1.64 \%$ in the HD group) (Figure 3B,D-F) and the ileum (an increase to $61.02 \pm 1.05 \%$ in the LD group and to $69.59 \pm 2.30 \%$ in the HD group) (Figure 3C). However, in the duodenum only in the HD group was the increase remarkable (to $68.35 \pm 1.40 \%$ ) (Figure 3A). In turn, in the OSP, in all fragments of the intestine under investigation, only in the HD group was an increased number of VIP-LI neurons simultaneously immunopositive to SP observed (an increase to $33.06 \pm 1.05 \%$ in the duodenum (Figure 3A,G-I), to $33.34 \pm 1.66 \%$ in the jejunum (Figure $3 \mathrm{~B}$ ) and to $34.6 \pm 1.4 \%$ in the ileum (Figure 3C), respectively). 

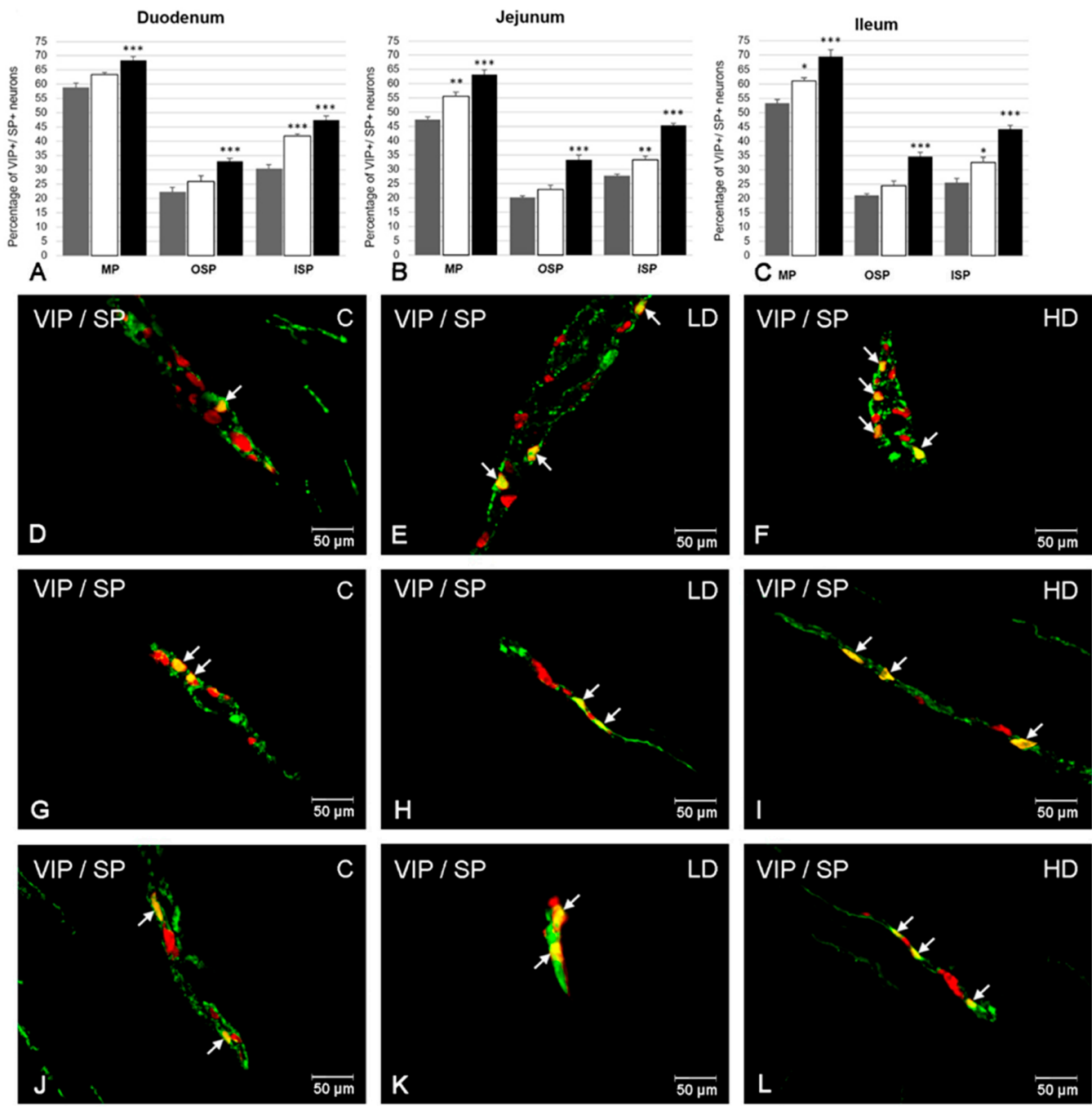

Figure 3. The ratio of co-localization of VIP with SP in intramural neurons in each part of the porcine small intestine (duodenum, jejunum, and ileum) in control animals (grey bars), after low (white bars) and high doses (black bars) of acrylamide supplementation $(\mathbf{A}-\mathbf{C})$ and the most representative images showing VIP-LI neurons simultaneously immunoreactive to substance $\mathrm{P}(\mathrm{SP})$ in animals from control $(\mathbf{D}, \mathbf{G}, \mathbf{J}), \mathrm{LD}(\mathbf{E}, \mathbf{H}, \mathbf{K}), \mathrm{HD}(\mathbf{F}, \mathbf{I}, \mathbf{L})$ group. (A) Mean $( \pm \mathrm{SEM})$ percentage of VIP+/SP+ neurons in the myenteric plexus (MP), outer submucous plexus (OSP), and inner submucous plexus (ISP) within the porcine duodenum; (B) Mean $( \pm \mathrm{SEM})$ percentage of $\mathrm{VIP}+/ \mathrm{SP}+$ neurons in the myenteric plexus (MP), outer submucous plexus (OSP), and inner submucous plexus (ISP) within the porcine jejunum; (C) Mean $( \pm \mathrm{SEM})$ percentage of $\mathrm{VIP}+/ \mathrm{SP}+$ neurons in the myenteric plexus $(\mathrm{MP})$, outer submucous plexus (OSP), and inner submucous plexus (ISP) within the porcine ileum; (D) VIP+/SP+ neurons in the myenteric plexus of the porcine jejunum in animals from control group; (E) VIP+/SP+ neurons in the myenteric plexus of the porcine jejunum in animals from LD group; (F) VIP+/SP+ neurons in the myenteric plexus of the porcine jejunum in animals from HD group; $(\mathrm{G}) \mathrm{VIP}+/ \mathrm{SP}+$ neurons in the outer submucous plexus (OSP) of the porcine duodenum in animals from control group; $(\mathbf{H}) \mathrm{VIP}+/ \mathrm{SP}+$ neurons in the outer submucous plexus (OSP) of the porcine duodenum in animals from LD group; (I) $\mathrm{VIP}+/ \mathrm{SP}+$ neurons in the outer submucous plexus (OSP) of the porcine duodenum in animals from HD group; (J) VIP+/SP+ neurons in the inner submucous plexus (ISP) of the porcine duodenum in animals from control group; (K) VIP+/SP+ neurons in the inner submucous plexus (ISP) of the porcine duodenum in animals from LD group; (L) VIP+/SP+ neurons in the inner submucous plexus (ISP) of the porcine duodenum in animals from HD group. All images were created by digital superimposition of two color channels (green for VIP and red for SP). Intramural neurons immunopositive to VIP and $\mathrm{SP}$ are indicated with arrows. Significant differences were assessed with one-way analysis of variance (ANOVA) with Dunnett's test $\left({ }^{*} p<0.05,{ }^{* *} p<0.01,{ }^{* * *} p<0.001\right)$. 


\subsection{The Co-Localization of VIP with CART}

Another substance co-localizing with VIP in intramural neurons was CART (Figure 4). In the MP, the percentage of neurons positive to both neuroactive substances was estimated at $37.25 \pm 1.25 \%$ in the duodenum (Figure 4A,D), $42.32 \pm 1.68 \%$ in the jejunum (Figure $4 \mathrm{~B}$ ) and $45.44 \pm 0.97 \%$ in the ileum (Figure 4C), respectively. In the OSP, the number of VIP-LI neurons that simultaneously expressed CART was similar in the jejunum (53.97 $\pm 1.41 \%$ ) (Figure 4B,G) and ileum $(50.59 \pm 0.92 \%)$ (Figure 4C). Slightly fewer VIP+/CART+ neurons were noted in the duodenum $(47.45 \pm 1.15 \%)$ (Figure $4 \mathrm{~A}$ ). In turn, in the ISP, a higher degree of co-localization of VIP with CART was observed in the jejunum $(46.18 \pm 1.09 \%)$ (Figure $4 \mathrm{~B})$ and duodenum $(43.81 \pm 1.36 \%$ ) (Figure $4 \mathrm{~A})$, while in the ileum this value amounted to $37.20 \pm 0.66 \%$ (Figure $4 \mathrm{C}, \mathrm{J}$ ).
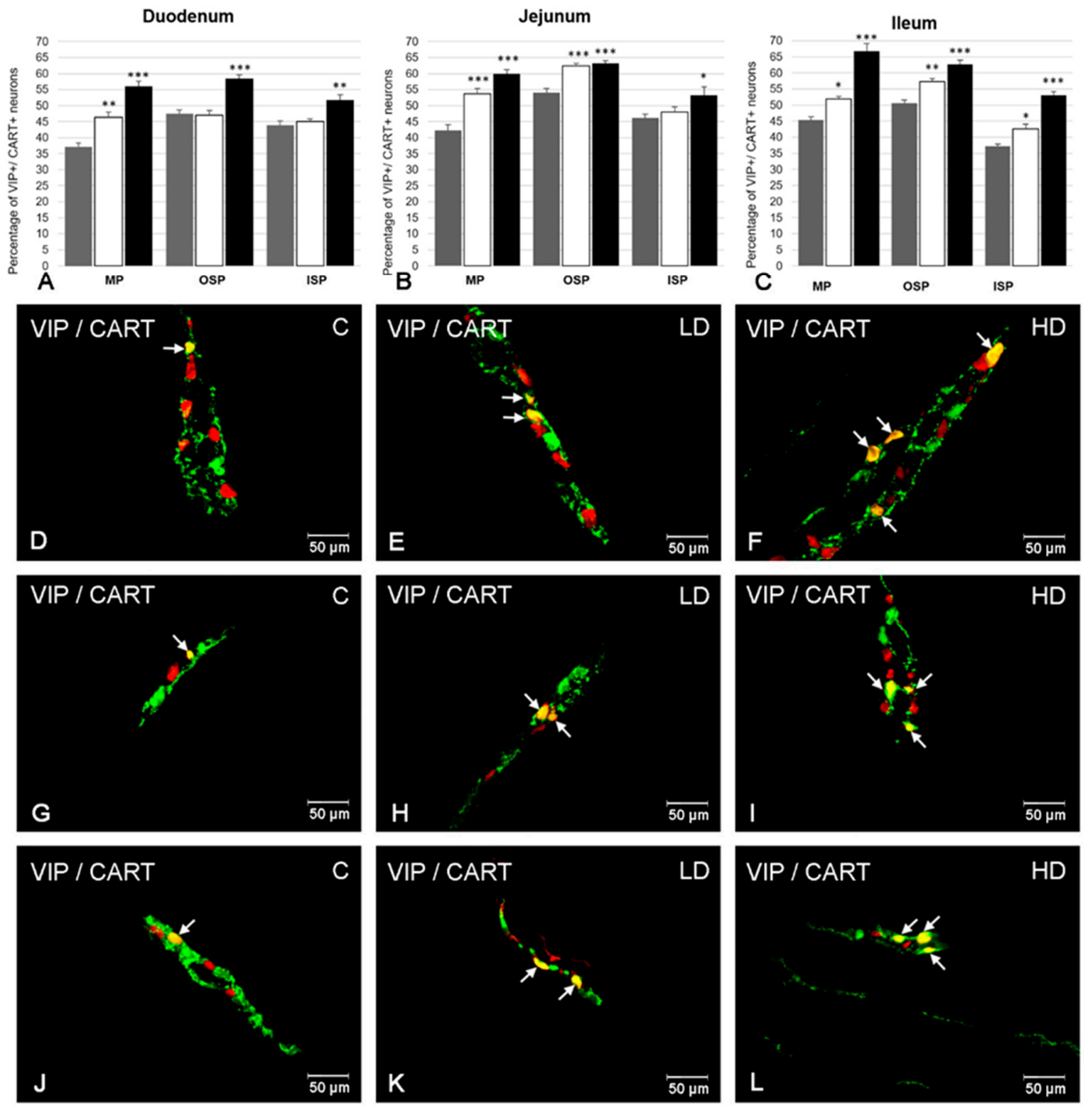

Figure 4. The ratio of co-localization of VIP with CART in intramural neurons in each part of the porcine small intestine (duodenum, jejunum, and ileum) in control animals (grey bars), after low (white bars) and high dose (black bars) of acrylamide supplementation (A-C) and the most representative images showing VIP-LI neurons simultaneously immunoreactive to CART in animals from control $(\mathbf{D}, \mathbf{G}, \mathbf{J}), \mathrm{LD}(\mathbf{E}, \mathbf{H}, \mathbf{K}), \mathrm{HD}(\mathbf{F}, \mathbf{I}, \mathbf{L})$ group. (A) Mean $( \pm \mathrm{SEM})$ percentage of VIP+/CART+ neurons in the myenteric plexus (MP), outer submucous plexus (OSP), and inner submucous plexus (ISP) within the porcine duodenum; $(\mathbf{B})$ Mean $( \pm S E M)$ percentage of VIP+/CART+ neurons in the myenteric plexus (MP), outer submucous plexus (OSP), and inner submucous plexus (ISP) within the porcine jejunum; (C) Mean $( \pm \mathrm{SEM})$ percentage of VIP+/CART+ neurons in the myenteric plexus $(\mathrm{MP})$, outer submucous 
plexus (OSP), and inner submucous plexus (ISP) within the porcine ileum; (D) VIP+/CART+ neurons in the myenteric plexus of the porcine duodenum in animals from control group; (E) VIP+/CART+ neurons in the myenteric plexus of the porcine duodenum in animals from LD group; (F) VIP+/CART+ neurons in the myenteric plexus of the porcine duodenum in animals from HD group; (G) VIP+/CART+ neurons in the outer submucous plexus (OSP) of the porcine jejunum in animals from control group; (H) VIP+/CART+ neurons in the outer submucous plexus (OSP) of the porcine jejunum in animals from LD group; (I) VIP+/CART+ neurons in the outer submucous plexus (OSP) of the porcine jejunum in animals from HD group; (J) VIP+/CART+ neurons in the inner submucous plexus (ISP) of the porcine ileum in animals from control group; (K) VIP+/CART+ neurons in the inner submucous plexus (ISP) of the porcine ileum in animals from LD group; (L) VIP+/CART+ neurons in the inner submucous plexus (ISP) of the porcine ileum in animals from HD group. All images were created by digital superimposition of two color channels (green for VIP and red for CART). Intramural neurons immunopositive to VIP and CART are indicated with arrows. Significant differences were assessed with one-way analysis of variance (ANOVA) with Dunnett's test $\left({ }^{*} p<0.05{ }^{* *} p<0.01\right.$, ${ }^{* * *} p<0.001$ ).

In the experimental groups, the number of VIP-LI neurons simultaneously immunopositive to CART increased in all segments of the small intestine and types of enteric plexus examined (Figure 4). The most visible changes were noted in the MP in both experimental groups and all segments of the small intestine, reaching the following values: in the duodenum, $46.41 \pm 1.64 \%$ in the LD group and $55.97 \pm 1.61 \%$ in the HD group (Figure $4 \mathrm{~A}, \mathrm{D}-\mathrm{F}$ ); in the jejunum, $53.70 \pm 1.68 \%$ in the LD group and $59.93 \pm 1.35 \%$ in the HD group (Figure $4 \mathrm{~B}$ ); in the ileum, $51.84 \pm 0.92 \%$ in the LD group and $66.80 \pm 2.30 \%$ in the HD group (Figure 4C). In turn, in the OSP both doses of acrylamide led to an increase in the percentage of VIP+/CART+ cell bodies in the jejunum (to $62.30 \pm 0.87 \%$ in the LD group and to $63.19 \pm 0.75 \%$ in the HD group) (Figure $4 \mathrm{~B}, \mathrm{G}-\mathrm{I}$ ) and in the ileum (to $57.23 \pm 1.09 \%$ in the LD group and to $62.60 \pm 1.41 \%$ in the HD group) (Figure $4 \mathrm{C}$ ). In the duodenum, only in the HD group an increase was noted (to $58.46 \pm 1.18 \%$ ) (Figure $4 \mathrm{~A}$ ). In turn, in the ISP, only in the ileum was the increase statistically important after supplementation of both acrylamide doses (to $42.56 \pm 1.52 \%$ in the LD group and to $53.10 \pm 1.16 \%$ in the HD group) (Figure $4 \mathrm{C}, \mathrm{J}-\mathrm{L}$ ), while in the duodenum and jejunum only in the HD group were an elevated number of VIP+/CART+ neurons noted (to $51.74 \pm 1.72 \%$ (Figure 4A) and to $53.25 \pm 2.58$ (Figure 4B), respectively).

\section{Discussion}

During this experiment, the presence of VIP was demonstrated in the ENS neurons in the porcine small intestine. In the physiological state, the number of VIP-LI neurons was similar in each kind of enteric plexus studied. This is comparable to previous studies conducted on the gut in the pig $[13,14,25]$. Moreover, the distribution of VIP in the structures of the ENS in the GI tract has been described in many other species of animals as well as in humans [26-28]. This is consistent with the numerous physiological functions of VIP in the digestive tract reported in the literature. First of all, VIP as an inhibitory neuropeptide inhibits gastric and intestinal motility. As the motor function is mainly regulated by the myenteric plexus, the VIP synthesized in the myenteric plexus is, with high probability, responsible for the inhibitory effect on the motor function. By contrast, VIP present in submucous neurons regulates the secretory function, such as ion secretion and fluid flow in the pancreas and intestine, and inhibits the secretion of digestive juices [19,29]. Additionally, VIP participates in the regeneration and control tight junction barrier function of the intestinal epithelium [30]. The multiple physiological functions of VIP are mediated via one of G-protein coupled receptors: VPAC1 (VIP/PACAP receptor, subtype 1) and VPAC2 (VIP/PACAP receptor) receptors binding VIP and PACAP, causing an increase in cyclic AMP and activating the protein kinase A pathway [31]. It was confirmed that most of the VIP functions in the intestine are performed through the VPAC1 receptor [32]. Furthermore, in the control group, VIP-positive ENS neurons simultaneously expressed other studied neuroactive substances. Previous studies showed that neurotransmitters synthetized in the same neurons possess a similar or auxiliary function [33]. The coexistence of nNOS, SP, and CART with VIP in ENS neurons in 
the small intestine suggests their complicity in the regulation of biological functions of this part of the GI tract in the pig.

The current study provides, for the first time, comprehensive data describing the effect of acrylamide supplementation on the population of VIP-LI neurons in the porcine small intestine. Both acrylamide doses (TDI and ten times higher) evoked changes in the expression of VIP in enteric neurons in each type of enteric plexus under investigation (i.e., MP, OSP, ISP). It is worth noting that inflammatory processes, neuronal damage, and many other harmful factors that the digestive tract is exposed to evoke functional changes in ENS neurons. These adaptive changes, including neuronal hyperplasia, degeneration of nerve endings, down or upregulation of neurotransmitter synthesis, and expression of their receptors, are an important line of defense and are known as neuronal plasticity [34]. The numerous studies conducted so far show that ACM has an adverse effect on living organisms, namely in demonstrating neurotoxic effects, reproductive disorders, and carcinogenicity $[1,4,5,9]$. Among them, neurotoxicity is of particular interest to researchers because this toxic effect has been described in both laboratory animals and humans (occupational exposure). The main clinical symptoms of ACM neurotoxicity include weakness, tingling and numbness in the extremities, convulsions, and ataxia [7]. It has been previously established that ACM led to the apoptosis of cerebellar Purkinje cells and the degeneration of axons and nerve terminals in the central and peripheral nervous systems [7,9]. Subsequent studies showed that ACM disrupted the neurotransmission by the inhibition of neurotransmitter release from the presynaptic membrane, i.e., reuptake and vesicular storage mainly via binding to nucleophilic cysteine sites on proteins [7,35]. Moreover, ACM inhibits Na+/K+-ATPase action [36] and fast axonal transport [37] and interferes with the work of enzymes involved in neuronal energy production [38]. Considering the known toxic effects of acrylamide on neurons, we can speculate that the increased number of VIP-LI neurons observed in the present study may have resulted from an inhibition of axonal transport induced by acrylamide. It is also highly probable that alteration in VIP immunoreactivity is a result of the increased synthesis of VIP in neuronal cells at various stages of this process (i.e., transcription, translation, or changes in the activity of enzymes involved in the synthesis) as a response on direct irritant effect of acrylamide on ENS neurons. The neuroprotective effect of VIP has been studied for many years in different experimental models. VIP exerts a potent neuroprotective effect through the activation of different signaling pathways and transcriptional-genetic activity. For instance, VIP decreases $A \beta$ accumulation and atrophy in the hippocampus and cortex in mice models of Alzheimer's disease [39], and it increases the spine density and prevents dopaminergic cell loss in rat models of Parkinson's disease [40]. Additionally, the survival effect of VIP on adult rat myenteric neurons in a culture was also confirmed [41]. The obtained results are comparable to previous results concerning the alteration of VIP immunoreactivity in enteric structures following pathophysiological situations through the digestive tract. Altered VIP levels in the ENS structure were found during nerve damage [13,22], diabetes [25], gastric ulcer [42], and bisphenol A intoxication [14].

Furthermore, numerous studies indicate that ACM, by the accumulation of excessive reactive oxygen species (ROS), causes oxidative stress and leads to damage in different organs of the body, including the brain, liver, and kidneys [43]. Notably, oxidative stress and enhanced lipid peroxidation are one of the main mechanisms of ACR-induced neurotoxicity [44]. The results obtained in the present study may be a response of ENS neurons to oxidative stress. Previous studies have indicated the potential role of VIP as a therapeutic agent that reduces oxidative stress and prevents cell damage caused by ROS [40,45].

Due to the anti-inflammatory properties of VIP, it can also be speculated that the increase in VIP-immunoreactivity in the ENS neurons is a response to local inflammation induced by acrylamide supplementation. The authors' earlier studies showed that acrylamide intoxication is accompanied by an increase in the synthesis of proinflammatory cytokines in the ileum wall [46]. Likewise, in human blood, an elevated concentration of high-sensitivity interleukin-6, high-sensitivity C-reactive protein, and gamma-glutamyl transferase concentrations was observed during the chronic intake of potato chips rich in acrylamide [47]. Earlier studies confirmed the participation of VIP in cross-talk between 
the ENS and enteric immune system. VIP effects were found on immune and inflammatory responses by promoting $\mathrm{T}$ helper cell differentiation, stimulating regulatory $\mathrm{T}$ cell synthesis, and downregulating macrophage action [34]. VIP was also shown to inhibit proinflammatory cytokine release (such as IL-6, TNF- $\alpha$, IL-12) and increase IL-10 synthesis [34,48]. Additionally, VIP exerts its anti-inflammatory effect by regulation of the epithelial barrier function, mainly by increasing the secretion of ions and fluids in the intestines and control of epithelial tight junction proteins synthesis [34,49]. There is also evidence that VIP acts directly on microglial cells as microglia-deactivating factors and, in this way, protect neurons against neuroinflammation [50]. Likewise, upregulated expression of VIP in the ENS structures was noted during inflammatory states in the GI tract, such as Helicobacter pylori infection [51], Crohn's disease [52], and ulcerative colitis [53].

In the current experiment, acrylamide-inducted alterations in the degree of the co-localization of VIP with nNOS, SP, and CART in the intramural neurons through the porcine small intestine was also demonstrated. Acrylamide supplementation increased the number of VIP-LI neurons simultaneously containing nNOS in all intramural plexuses examined. Changes were visible in both experimental groups and depended on the kind of plexus and the part of the intestine under investigation. Several lines of evidence show that NO possesses neuroprotective properties and also has a regulatory role in many inflammatory processes $[33,54]$. To date, an increased number of nNOS-LI enteric neurons were noted in inflammatory bowel disease [55] after denervation [56] or bisphenol A administration [57]. Similar to VIP, nNOS has a beneficial effect on the survival rate of cultured rat colonic submucous neurons [58]. However, some pathological conditions in the gut, such as diabetes or Crohn's disease, may lead to a reduction in the population of nitrergic neurons in the gut wall [59]. It is highly probable that the role of nNOS in the control of pathological conditions in the GI tract depends on the type of harmful factors and type of inflammation as well as the section of the GI tract studied.

Another substance co-localized with VIP in the ENS neurons in the porcine small intestine was SP. In this case, both doses of acrylamide also led to an increase in the population of VIP+/SP+ neurons in all studied enteric plexuses. The changes were the most significant in the ISP and MP. However, in the OSP, only a high dose caused significant changes. Alterations in the SP level in the nervous structures located in the intestinal wall have been described in numerous pathological states, such as inflammatory bowel disease [60], Bacteroides fragilis [61] and Trypanosoma cruzi infection [62], bisphenol A intoxication [14], and neoplastic diseases [63]. Previous studies have indicated the possible role of SP in the control of inflammatory conditions. SP stimulates the synthesis of TNF- $\alpha$, IL-1 $\beta$, and IL-6 in the human colonic mucosa [64], increases the production of IL-1 $\beta$ and IL-6 mRNA in human glial cells, and co-operates with mast cells in the wall of ileum and ascending colon of irritable bowel syndrome (IBS) patients $[65,66]$. Therefore, the observed changes in the present study in a population of VIP+/SP+ neurons may be associated with local inflammation caused by acrylamide supplementation. However, since SP is involved in pain transmission, it can also be speculated that the observed changes may be a result of a pain condition accompanying acrylamide intoxication.

Finally, a significant increase in the number of VIP-LI neurons simultaneously containing CART was observed after the administration of both acrylamide doses, and the changes were the most remarkable in the MP. Slightly smaller changes were noted in the submucous plexuses. In recent years, many studies have revealed that CART exerts neuroprotective effects. It was established that CART is engaged in protection against the ischemic cerebral injury by reducing inflammation activation and inhibiting oxidative stress and protecting mitochondrial functions [67]. Changes in CART immunoreactivity in both nerve fibers, as well as neuron cell bodies in the GI tract wall, were also described following numerous pathological conditions. An upregulated level of CART accompanying proliferative enteropathy of the descending colon [68] and axotomy [69] in pigs as well as hypertension in rats [70] were noted. Additionally, Ekblad [71] reported that CART enhances neuronal survival of culturing myenteric neurons in rats. Although the mechanism of CART neuroprotective action has not been fully elucidated, the research carried out to date and the results of this experiment suggest that it plays a neuroprotective and neurotrophic role in the intestines. Based on the well-known 
anti-inflammatory and neuroprotective activities of VIP, it can be concluded that they are involved in the protection of ENS neurons against the harmful effects of acrylamide in the porcine small intestine and cooperate in this process with nNOS, SP, and CART. The obtained results here are the basis for further pharmacological and clinical study. In the future, agonists of VPAC receptors may be potentially useful agents in managing the toxic effects evoked by acrylamide supplementation. However, further research is needed to better understand the function and the exact mechanism of action of these substances in the course of acrylamide intoxication.

\section{Material and Methods}

In the experiment, 15 Danish landrace gilts purchased from a local farm and of about $15 \mathrm{~kg}$ body weight (b.w.) were used. The animals were group-housed in age-appropriate cages, fed commercial feed, and had constant access to water. All experimental procedures carried out on animals were approved by the Local Commission for Animal Experiments in Olsztyn (decision no. 11/2017, 28 February 2017). After a 7-day acclimatization period, the animals were assigned to one of three experimental groups: (a) the control (C group), i.e., gilts receiving empty gelatin capsules; (b) a low-dose group (LD group, $n=5)$, gilts receiving a tolerable daily intake (TDI) dose $(0.5 \mu \mathrm{g} / \mathrm{kg} \mathrm{b.w./day)} \mathrm{of} \mathrm{acrylamide} \mathrm{(}>99 \%$; Sigma-Aldrich, Poznań, Poland) in gelatin capsules; and (c) a high-dose group (the HD group, $n=5$ ), i.e., gilts receiving a high dose of acrylamide (ten times higher than TDI, i.e., $5 \mu \mathrm{g} / \mathrm{kg}$ b.w./day) in gelatin capsules. The capsules were administered in the same manner to all animals for a period of 28 days with their morning feeding. After this time, the gilts of all groups were euthanized with sodium pentobarbital (Morbital, Biowet Puławy, Puławy, Poland), and fragments of the small intestine (duodenum, jejunum, and ileum) were collected for further examination. Tissues were fixed by immersion in a $4 \%$ buffered solution of paraformaldehyde ( $\mathrm{pH} 7.4$ ) for one hour and transferred to a phosphate buffer solution (PBS, pH 7.4) for $72 \mathrm{~h}$ (a buffer was exchanged 3 times, every $24 \mathrm{~h}$ ). The tissues were then placed into an $18 \%$ buffered sucrose solution for two weeks. After this period, $14 \mu \mathrm{m}$ thick frozen sections were prepared and subjected to the procedure of double immunofluorescence staining as described previously by Palus et al. [72].

Briefly, sections were dried at room temperature for $45 \mathrm{~min}$, then washed in a buffer solution (PBS, 3 times, $10 \mathrm{~min}$ ), blocked in a blocking mixture (10\% horse serum, $0.1 \%$ bovine serum albumin in $0.1 \mathrm{M}$ PBS, $1 \%$ Triton X-100, $0.05 \%$ thimerosal, and $0.01 \%$ sodium aside) for $1 \mathrm{~h}$, rinsed again in the PBS ( 3 times, $10 \mathrm{~min}$ ), and then placed into the primary antibody mixture consisting of a protein gene-product 9.5 (PGP 9.5; mouse, cat. No. 7863-2004, Bio-Rad, Hercules, CA, USA, working dilution 1:1000, used here as a pan-neuronal marker) and vasoactive intestinal peptide (VIP; rabbit, cat. No. 11428, Cappel, Aurora, OH, USA, working dilution 1:3000), as well as VIP (mouse, cat. No. 9535-0504, Biogenesis Inc., Poole, UK, working dilution 1: 2000), neuronal nitric oxide synthase (nNOS; rabbit, cat. No. AB5380, Sigma-Aldrich, Saint Louis, MO, USA, working dilution 1:2000), substance P (SP, rat monoclonal, AbD Serotec, Raleigh, NC, USA; Cat. \# 8450-0505; working dilution 1:150), cocaine- and amphetamine-regulated transcript peptide (CART; rabbit, cat. No. H-003-61, Phoenix Pharmaceuticals, Burlingame, CA, USA, working dilution 1:8000), and incubated overnight in a humid chamber.

On the second day, the sections were washed in the PBS (three times, $10 \mathrm{~min}$ ) and incubated with a mixture of secondary antibodies (Alexa Fluor 488 (donkey anti-mouse IgG, cat. No. A21202, Invitrogen, Carlsbad, CA, USA, working dilution 1:1000)), Alexa Fluor 546 (goat anti-rabbit IgG, cat. No. A11010, Invitrogen, Carlsbad, CA, USA, working dilution 1:1000), and Alexa Fluor 546 (donkey anti-rat, cat. No. A21208, Invitrogen, Carlsbad, CA, USA, working dilution 1:1000) at room temperature for $1 \mathrm{~h}$. After another wash in the PBS, the sections were coverslipped using a mixture of glycerol with carbonate buffer $(\mathrm{pH}=8.4)$. To assess the specificity of the method, standard controls were used, including replacement, omission, and preabsorption tests.

The stained sections were analyzed under an epifluorescence microscope and then photographed using a digital camera connected to a computer with Olympus Cell F image analysis software (Olympus, Tokyo, Japan). The number of ENS neurons showing immunoreactivity against VIP in particular 
plexus types (i.e., MP, ISP, OSP) in all three sections of the small intestine (duodenum, jejunum, ileum) was determined as the percentage of PGP 9.5 immunoreactive neurons (pan-neuronal marker). No less than 500 PGP 9.5 neurons in each of the analyzed plexuses were used for counting in sections separated at least $200 \mu \mathrm{m}$ from each other. The degree of VIP co-localization with nNOS, SP, and CART was determined by counting at least 100 VIP-LI neurons in each plexus type (MP, ISP, OSP) for all antisera combinations. In this analysis, VIP-LI neurons were considered as $100 \%$. Data were pooled and expressed as a mean \pm standard error of mean (SEM). Statistical analysis were performed with Statistica 12 software (StatSoft Inc., Tulsa, OK, USA) using a one-way analysis of variance (ANOVA) with Dunnett's test $\left({ }^{*} p<0.05,{ }^{* *} p<0.01,{ }^{* * *} p<0.001\right)$.

\section{Conclusions}

In conclusion, acrylamide administration increased the population of VIP-LI intramural neurons in the porcine small intestine. Moreover, both doses of acrylamide led to changes in the degree of co-localization of VIP with nNOS, SP, and CART in all types of ENS plexuses and fragments of small intestine studied. The observed changes may be the adaptation of neurons to local inflammation, oxidative stress or the direct toxic effects of acrylamide on intestinal neurons referred to as neuronal plasticity. The low doses of acrylamide used in the experiment (corresponding to the real human exposure to this toxin) induced a significant response of ENS neurons in all sections of the porcine small intestine. Therefore, it should be considered whether the current legal regulations are sufficient to ensure the safety of food products containing acrylamide. These studies may become the starting point for further toxicological and pharmacological studies. In the future, VIP and/or its receptor agonists may potentially act as therapeutic agents to protect ENS neurons from the harmful effects of acrylamide contained in food products.

Author Contributions: Conceptualization, K.P.; investigation, K.P. and M.B.; methodology, K.P.; writing-original draft, K.P.; writing-review and editing, J.C. All authors have read and agreed to the published version of the manuscript.

Funding: Funded by KNOW (Leading National Research Centre) Scientific Consortium "Healthy Animal—Safe Food", decision of Ministry of Science and Higher Education No. 05-1/KNOW2/2015 and the University of Warmia and Mazury in Olsztyn (statutory research) grant No 15.610.003-300. Project financially co-supported by Minister of Science and Higher Education in the range of the program entitled "Regional Initiative of Excellence" for the years 2019-2022, Project No. 010/RID/2018/19, amount of funding 12.000.000 PLN.

Conflicts of Interest: The authors declare no conflict of interest.

\section{References}

1. Dybing, E.; Farmer, P.B.; Andersen, M.; Fennell, T.R.; Lalljie, S.P.; Müller, D.J.; Olin, S.; Petersen, B.J.; Schlatter, J.; Scholz, G.; et al. Human exposure and internal dose assessments of acrylamide in food. Food Chem. Toxicol. 2005, 43, 365-410. [CrossRef]

2. Van Lancker, F.; Adams, A.; De Kimpe, N. Chemical modifications of peptides and their impact on food properties. Chem. Rev. 2011, 111, 7876-7903. [CrossRef]

3. WHO. Health Implications of Acrylamide in Food; FAO: Rome, Italy; WHO: Geneva, Switzerland, 2002. Available online: http://apps.who.int/iris/handle/10665/42563 (accessed on 15 April 2019).

4. Shipp, A.; Lawrence, G.; Gentry, R.; McDonald, T.; Bartow, H.; Bounds, J.; Macdonald, N.; Clewell, H.; Allen, B.; Van Landingham, C. Acrylamide: Review of toxicity data and dose-response analyses for cancer and noncancer effects. Crit. Rev. Toxicol. 2006, 36, 481-608. [CrossRef]

5. Lee, S.; Park, H.R.; Lee, J.Y.; Cho, J.H.; Song, H.M.; Kim, A.H.; Lee, W.; Lee, Y.; Chang, S.C.; Kim, H.S.; et al. Learning, memory deficits, and impaired neuronal maturation attributed to acrylamide. J. Toxicol. Environ. Health A 2018, 81, 254-265. [CrossRef]

6. IARC. Acrylamide. In IARC Monographs on the Evaluation of the Carcinogenic Risk of Chemicals to Humans; IARC: Lyon, France, 1994; Volume 60, pp. 389-433.

7. Lo Pachin, R.M. The changing view of acrylamide neurotoxicity. Neurotoxicology 2004, 25, 617-630. [CrossRef] 
8. Zödl, B.; Schmid, D.; Wassler, G.; Gundacker, C.; Leibetseder, V.; Thalhammer, T.; Ekmekcioglu, C. Intestinal transport and metabolism of acrylamide. Toxicology 2007, 232, 99-108. [CrossRef]

9. De Giorgio, R.; Barbara, G.; Pinto, D.; Cogliandro, R.; Elia, G.; Tomassetti, P.; Gizzi, G.; Stanghellini, V.; Corinaldesi, R. The innervation of the digestive tract: Its morphofunctional and neurochemical aspects. Minerva Gastroenterol. Dietol. 1996, 42, 83-91.

10. Furness, J.B.; Callaghan, B.P.; Rivera, L.R.; Cho, H.J. The enteric nervous system and gastrointestinal innervation: Integrated local and central control. Adv. Exp. Med. Biol. 2014, 817, 39-71.

11. Gonkowski, S. Substance $P$ as a neuronal factor in the enteric nervous system of the porcine descending colon in physiological conditions and during selected pathogenic processes. Biofactors 2013, 39, 542-551. [CrossRef]

12. Furness, J.B. Types of neurons in the enteric nervous system. J. Auton. Nerv. Syst. 2000, 81, 87-96. [CrossRef]

13. Makowska, K. Chemically induced inflammation and nerve damage affect the distribution of vasoactive intestinal polypeptide-like immunoreactive (VIP-LI) nervous structures in the descending colon of the domestic pig. Neurogastroenterol Motil. 2018, 30, e13439. [CrossRef]

14. Szymanska, K.; Gonkowski, S. Bisphenol A-Induced changes in the enteric nervous system of the porcine duodenum. Neurotoxicology 2018, 66, 78-86. [CrossRef]

15. Said, S.I.; Mutt, V. Polypeptide with broad biological activity: Isolation from small intestine. Science 1970, 169, 1217-1218. [CrossRef]

16. Iwasaki, M.; Akiba, Y.; Kaunitz, J.D. Recent advances in vasoactive intestinal peptide physiology and pathophysiology: Focus on the gastrointestinal system. F1000Research 2019, 8, 1629. [CrossRef]

17. Waschek, J.A.; Bravo, D.T.; Sena, M.; Casillas, R.; Rodriguez, W.; Nguyen, T.; Colburn, S. Targeting of embryonic and postnatal autonomic and enteric neurons with a vasoactive intestinal peptide transgene. J. Neurochem. 1999, 73, 1739-1748. [CrossRef]

18. Palle, C.; Ottesen, B.; Jørgensen, J.; Fahrenkrug, J. Peptide histidine methionine and vasoactive intestinal peptide: Occurrence and relaxant effect in the human female reproductive tract. Biol. Reprod. 1989, 41, 1103-1111. [CrossRef]

19. Biancani, P.; Walsh, J.H.; Behar, J. Vasoactive intestinal polypeptide. A neurotransmitter for lower esophageal sphincter relaxation. J. Clin. Investig. 1984, 73, 963-967. [CrossRef]

20. Zhao, D.Q.; Xue, H.; Sun, H.J. Nervous mechanisms of restraint water-immersion stress-induced gastric mucosal lesion. World J. Gastroenterol. 2020, 26, 2533-2549. [CrossRef]

21. Deng, G.; Jin, L. The effects of vasoactive intestinal peptide in neurodegenerative disorders. Neurol. Res. 2016, 39, 65-72. [CrossRef]

22. Ekblad, E.; Bauer, A.J. Role of vasoactive intestinal peptide and inflammatory mediators in enteric neuronal plasticity. Neurogastroenterol. Motil. 2004, 16, 123-128. [CrossRef]

23. Moody, T.W.; Nuche-Berenguer, B.; Jensen, R.T. Vasoactive intestinal peptide/pituitary adenylate cyclase activating polypeptide, and their receptors and cancer. Curr. Opin. Endocrinol. Diabetes Obes. 2016, 23, 38-47. [CrossRef] [PubMed]

24. Verma, N.; Rettenmeier, A.W.; Schmitz-Spanke, S. Recent advances in the use of Sus scrofa (pig) as a model system for proteomic studies. Proteomics 2011, 11, 776-793. [CrossRef] [PubMed]

25. Bulc, M.; Palus, K.; Zielonka, Ł.; Gajęcka, M.; Całka, J. Changes in expression of inhibitory substances in the intramural neurons of the stomach following streptozotocin-induced diabetes in the pig. World J. Gastroenterol. 2017, 23, 6088-6099. [CrossRef] [PubMed]

26. Pimont, S.; Bruley Des Varannes, S.; Le Neel, J.C.; Aubert, P.; Galmiche, J.P.; Neunlist, M. Neurochemical coding of myenteric neurones in the human gastric fundus. Neurogastroenterol. Motil. 2003, 15, 655-662. [CrossRef]

27. Toole, L.; Belai, A.; Burnstock, G. A neurochemical characterisation of the golden hamster myenteric plexus. Cell Tissue Res. 1998, 291, 385-394. [CrossRef]

28. Matini, P.; Mayer, B.; Faussone-Pellegrini, M.S. Neurochemical differentiation of rat enteric neurons during pre- and postnatal life. Cell Tissue Res. 1997, 288, 11-23. [CrossRef]

29. Coupar, I.M. Stimulation of sodium and water secretion without inhibition of glucose absorption in the rat jejunum by vasoactive intestinal peptide(VIP). Clin. Exp. Pharmacol. Physiol. 1976, 3, 615-618. [CrossRef] 
30. Toumi, F.; Neunlist, M.; Cassagnau, E.; Parois, S.; Laboisse, C.L.; Gal-miche, J.P.; Jarry, A. Human submucosal neurones regulate intestinal epithelial cell proliferation: Evidence from a novel co-culture model. Neurogastroenterol. Motil. 2003, 15, 239-242. [CrossRef] [PubMed]

31. Laburthe, M.; Couvineau, A.; Tan, V. Class II G protein-coupled receptors for VIP and PACAP: Structure, models of activation and pharmacology. Peptides 2007, 28, 1631-1639. [CrossRef]

32. Jayawardena, D.; Guzman, G.; Gill, R.K.; Alrefai, W.A.; Onyuksel, H.; Dudeja, P.K. Expression and localization of VPAC1, the major receptor of vasoactive intestinal peptide along the length of the intestine. Am. J. Physiol. Gastrointest. Liver Physiol. 2017, 313, G16-G25. [CrossRef]

33. Bulc, M.; Palus, K.; Dąbrowski, M.; Całka, J. Hyperglycaemia-Induced Downregulation in Expression of nNOS Intramural Neurons of the Small Intestine in the Pig. Int. J. Mol. Sci. 2019, 20, 1681. [CrossRef]

34. Chandrasekharan, B.; Nezami, B.G.; Srinivasan, S. Emerging neuropeptide targets in inflammation: NPY and VIP. Am. J. Physiol. Gastrointest. Liver Physiol. 2013, 304, G949-G957. [CrossRef] [PubMed]

35. Barber, D.S.; Stevens, S.; LoPachin, R.M. Proteomic analysis of rat striatal synaptosomes during acrylamide intoxication at a low dose rate. Toxicol. Sci. 2007, 100, 157-167. [CrossRef]

36. LoPachin, R.M., Jr.; Lehning, E.J. Acrylamide-induced distal axon degeneration: A proposed mechanism of action. Neurotoxicology 1994, 15, 247-259.

37. Sickles, D.W.; Stone, J.D.; Friedman, M.A. Fast axonal transport: A site of acrylamide neurotoxicity? Neurotoxicology 2002, 23, 223-251. [CrossRef]

38. LoPachin, R.M.; Gavin, T. Molecular mechanism of acrylamide neurotoxicity: Lessons learned from organic chemistry. Environ. Health Perspect. 2012, 120, 1650-1657. [CrossRef] [PubMed]

39. Korkmaz, O.T.; Ay, H.; Aytan, N.; Carreras, I.; Kowall, N.W.; Dedeoglu, A.; Tuncel, N. Vasoactive Intestinal Peptide Decreases $\beta$-Amyloid Accumulation and Prevents Brain Atrophy in the 5xFAD Mouse Model of Alzheimer's Disease. J. Mol. Neurosci. 2019, 68, 389-396. [CrossRef]

40. Tunçel, N.; Korkmaz, O.T.; Tekin, N.; Şener, E.; Akyüz, F.; Inal, M. Antioxidant and anti-apoptotic activity of vasoactive intestinal peptide (VIP) against 6-hydroxy dopamine toxicity in the rat corpus striatum. J. Mol. Neurosci. 2012, 46, 51-57. [CrossRef]

41. Sandgren, K.; Lin, Z.; Fex Svenningsen, A.; Ekblad, E. Vasoactive intestinal peptide and nitric oxide promote survival of adult rat myenteric neurons in culture. J. Neurosci. Res. 2003, 72, 595-602. [CrossRef]

42. Rozza, A.L.; Moraes Tde, M.; Kushima, H.; Tanimoto, A.; Marques, M.O.; Bauab, T.M.; Hiruma-Lima, C.A.; Pellizzon, C.H. Gastroprotective mechanisms of Citrus lemon (Rutaceae) essential oil and its majority compounds limonene and $\beta$-pinene: Involvement of heat-shock protein-70, vasoactive intestinal peptide, glutathione, sulfhydryl compounds, nitric oxide and prostaglandin $\mathrm{E}_{2}$. Chem. Biol. Interact. 2011, 189, 82-89. [CrossRef]

43. Yousef, M.I. El-Demerdash FM. Acrylamide-induced oxidative stress and biochemical perturbations in rats. Toxicology 2006, 219, 133-141. [CrossRef] [PubMed]

44. Guo, J.; Cao, X.; Hu, X.; Li, S.; Wang, J. The anti-apoptotic, antioxidant and anti-inflammatory effects of curcumin on acrylamide-induced neurotoxicity in rats. BMC Pharmacol. Toxicol. 2020, 21, 62. [CrossRef] [PubMed]

45. Fujimori, N.; Oono, T.; Igarashi, H.; Ito, T.; Nakamura, T.; Uchida, M.; Coy, D.H.; Jensen, R.T.; Takayanagi, R. Vasoactive intestinal peptide reduces oxidative stress in pancreatic acinar cells through the inhibition of NADPH oxidase. Peptides 2011, 32, 2067-2076. [CrossRef] [PubMed]

46. Palus, K.; Obremski, K.; Bulc, M.; Całka, J. The impact of low and high doses of acrylamide on the intramural neurons of the porcine ileum. Food Chem. Toxicol. 2019, 132, 110673. [CrossRef]

47. Naruszewicz, M.; Zapolska-Downar, D.; Ko’smider, A.; Nowicka, G.; Kozłowska-Wojciechowska, M.; Vikström, A.S.; Törnqvist, M. Chronic intake of potato chips in humans increases the production of reactive oxygen radicals by leukocytes and increases plasma C-reactive protein: A pilot study. Am. J. Clin. Nutr. 2009, 89, 773-777. [CrossRef] [PubMed]

48. Erendor, F.; Sahin, E.O.; Sanlioglu, A.D.; Balci, M.K.; Griffith, T.S.; Sanlioglu, S. Lentiviral gene therapy vectors encoding VIP suppressed diabetes-related inflammation and augmented pancreatic beta-cell proliferation. Gene Ther. 2020. [CrossRef]

49. Banks, M.R.; Farthing, M.J.; Robberecht, P.; Burleigh, D.E. Antisecretory actions of a novel vasoactive intestinal polypeptide (VIP) antagonist in human and rat small intestine. Br. J. Pharmacol. 2005, 144, 994-1001. [CrossRef] 
50. Carniglia, L.; Ramírez, D.; Durand, D.; Saba, J.; Turati, J.; Caruso, C.; Scimonelli, T.N.; Lasaga, M. Neuropeptides and Microglial Activation in Inflammation, Pain, and Neurodegenerative Diseases. Mediators Inflamm. 2017, 2017, 5048616. [CrossRef]

51. Li, X.B.; Chen, H.M.; Lu, H.; Zheng, Q.; Chen, X.Y.; Peng, Y.S.; Ge, Z.Z.; Liu, W.Z. Role of Helicobacter pylori infection on neuronal expression in the stomach and spinal cord of a murine model. J. Dig. Dis. 2009, 10, $286-292$. [CrossRef]

52. Arranz, A.; Abad, C.; Juarranz, Y.; Leceta, J.; Martinez, C.; Gomariz, R.P. Vasoactive intestinal peptide as a healing mediator in Crohn's disease. Neuroimmunomodulation 2008, 15, 46-53. [CrossRef]

53. Abad, C.; Cheung-Lau, G.; Coûté-Monvoisin, A.C.; Waschek, J.A. Vasoactive intestinal peptide-deficient mice exhibit reduced pathology in trinitrobenzene sulfonic acid-induced colitis. Neuroimmunomodulation 2015, 22, 203-212. [CrossRef] [PubMed]

54. Shah, V.; Lyford, G.; Gores, G.; Farrugia, G. Nitric oxide in gastrointestinal health and disease. Gastroenterology 2004, 126, 903-913. [CrossRef] [PubMed]

55. Rychlik, A.; Gonkowski, S.; Nowicki, M.; Calka, J. Inflammatory bowel disease affects density of nitrergic nerve fibers in the mucosal layer of the canine gastrointestinal tract. Can. J. Vet. Res. 2017, 81, 129-136. [PubMed]

56. Yunker, A.M.; Galligan, J.J. Extrinsic denervation increases myenteric nitric oxide synthase-containing neurons and inhibitory neuromuscular transmission in guinea pig. J. Auton. Nerv. Syst. 1998, 71, 148-158. [CrossRef]

57. Szymanska, K.; Calka, J.; Gonkowski, S. Nitric oxide as an active substance in the enteric neurons of the porcine digestive tract in physiological conditions and under intoxication with bisphenol A (BPA). Nitric. Oxide. 2018, 80, 1-11. [CrossRef] [PubMed]

58. Lin, Z.; Sandgren, K.; Ekblad, E. Increased expression of nitric oxide synthase in cultured neurons from adult rat colonic submucous ganglia. Auton. Neurosci. 2004, 114, 29-38. [CrossRef] [PubMed]

59. Winston, J.H.; Li, Q.; Sarna, S.K. Paradoxical regulation of ChAT and nNOS expression in animal models of Crohn's colitis and ulcerative colitis. Am. J. Physiol. Gastrointest. Liver Physiol. 2013, 305, G295-G302. [CrossRef] [PubMed]

60. Weinstock, J.V. Substance P and the regulation of inflammation in infections and inflammatory bowel disease. Acta Physiol. 2015, 213, 453-461. [CrossRef]

61. Gonkowski, S.; Kamińska, B.; Bossowska, A.; Korzon, M.; Landowski, P.; Majewski, M. The influence of experimental Bacteroides fragilis infection on substance $\mathrm{P}$ and somatostatin-immunoreactive neural elements in the porcine ascending colon-A preliminary report. Folia Morphol. 2003, 62, 455-457.

62. Nascimento, R.D.; Martins, P.R.; de Souza Lisboa, A.; Adad, S.J.; Morais da Silveira, A.B.; Reis, D. An imbalance between substance $P$ and vasoactive intestinal polypeptide might contribute to the immunopathology of megaesophagus after Trypanosoma cruzi infection. Hum. Pathol. 2013, 44, 269-276. [CrossRef]

63. Muñoz, M.; Coveñas, R. Involvement of substance P and the NK-1 receptor in cancer progression. Peptides 2013, 48, 1-9. [CrossRef] [PubMed]

64. Dai, L.; Perera, D.S.; Burcher, E.; Liu, L. Hemokinin-1 and substance P stimulate production of inflammatory cytokines and chemokines in human colonic mucosa via both $\mathrm{NK}(1)$ and $\mathrm{NK}(2)$ tachykinin receptors. Neuropeptides 2020, 82, 102061. [CrossRef] [PubMed]

65. Berger, A.; Paige, C.J. Hemokinin-1 has Substance P-like function in U-251 MG astrocytoma cells: A pharmacological and functional study. J. Neuroimmunol. 2005, 164, 48-56. [CrossRef] [PubMed]

66. Wang, L.H.; Fang, X.C.; Pan, G.Z. Bacillary dysentery as a causative factor of irritable bowel syndrome and its pathogenesis. Gut 2004, 53, 1096-1101. [CrossRef]

67. Zhang, Z.; Cao, X.; Bao, X.; Zhang, Y.; Xu, Y.; Sha, D. Cocaine- and amphetamine-regulated transcript protects synaptic structures in neurons after ischemic cerebral injury. Neuropeptides 2020,81, 102023. [CrossRef]

68. Gonkowski, S.; Burliński, P.; Szwajca, P.; Całka, J. Changes in cocaine- and amphetamine-regulated transcript-like immunoreactive (CART-LI) nerve struc-tures of the porcine descending colon during proliferative enteropathy. Bull. Vet. Inst. Pulawy 2012, 56, 199-203. [CrossRef]

69. Burliński, P.J. Inflammation- and axotomy-induced changes in cocaine- and amphetamine-regulated transcript peptide-like immunoreactive (CART-LI) nervous structures in the porcine descending colon. Pol. J. Vet. Sci. 2012, 15, 517-524. [CrossRef]

70. Kasacka, I.; Piotrowska, Z. Evaluation of density and distribution of CART-immunoreactive structures in gastrointestinal tract of hypertensive rats. Biofactors 2012, 38, 407-415. [CrossRef]

71. Ekblad, E. CART in the enteric nervous system. Peptides 2006, 27, 2024-2030. [CrossRef] 
72. Palus, K.; Bulc, M.; Całka, J. Changes in VIP-, SP- and CGRP- like immunoreactivity in intramural neurons within the pig stomach following supplementation with low and high doses of acrylamide. Neurotoxicology 2018, 69, 47-59. [CrossRef]

Publisher's Note: MDPI stays neutral with regard to jurisdictional claims in published maps and institutional affiliations.

(C) 2020 by the authors. Licensee MDPI, Basel, Switzerland. This article is an open access article distributed under the terms and conditions of the Creative Commons Attribution (CC BY) license (http://creativecommons.org/licenses/by/4.0/). 